\title{
Finasteride promotes worsening of the cardiac deleterious effects of nandrolone decanoate and protects against genotoxic and cytotoxic damage
}

\author{
Elizângela Faustino Da Mata ${ }^{1, \S}$, Andrews Marques do Nascimentoํㅜ, Ewelyne Miranda de Lima ${ }^{1}$, \\ Ieda Carneiro Kalil ${ }^{1}$, Denise Coutinho Endringer ${ }^{1}$, Dominik Lenz ${ }^{1}$, Nazaré Souza Bissoli ${ }^{2}$, \\ Girlandia Alexandre Brasil ${ }^{1 *}$, Tadeu Uggere de Andrade ${ }^{\circledR 1 *}$
}

\author{
${ }^{1}$ Pharmaceutical Sciences Graduate Program, University Vila Velha, Vila Velha, ES, Brazil, ${ }^{2}$ Department of Physiological \\ Sciences, Health Sciences Center, Federal University of Espírito Santo, Vitória, ES, Brazil
}

\begin{abstract}
Metabolism of anabolic androgenic steroids is important for its physiological effects. The aim was to investigate the effects of finasteride (a $5 \alpha$-reductase inhibitor $-5 \alpha \mathrm{R}$ ) on cardiac and mutagenic effects promoted by ND. Male Wistar rats were separated into three groups: CONT, received the vehicles of ND and finasteride (Peanut oil+Saline); DECA group, received ND (20 mg.kg.week ${ }^{-1}$, i.m.), and DECAF received ND and finasteride $\left(100 \mu \mathrm{g} . \mathrm{kg}^{-1}\right.$, i.p.), for four weeks. After, hypertrophy, cytokines and Angiotensin Converting Enzyme (ACE) activity was determined in heart. Bone marrow was used for micronucleus evaluation. Treatment with ND promotes increase in cardiac hypertrophy, ACE activity and disbalance among pro- and anti-inflammatory cytokines, and combination with finasteride worsened those effects. Association with finasteride ameliorates the toxic effects of ND on bone marrow cells, as was observed by a normalization of the number of micronucleate polychromatic erythrocytes and the mitotic index. Our data demonstrates that deleterious effects promoted by ND are depend, at least in part, of its metabolization. Also, inhibition of $5 \alpha \mathrm{R}$ by finasteride present variated effects dependent on organ studied. It can promote increase on cardiac damage and a reduction on mutagenic effects of ND, which demonstrated that dehydronandrolone has diverse role on ND effects..
\end{abstract}

Keywords: Dehydronandrolone. Finasteride. Mutagenicity. Cardiac Hypertrophy. Anabolic Androgenic Steroids.

\section{INTRODUCTION}

Anabolic androgenic steroids (AASs) are synthetic drug analogs of the endogenous hormone testosterone. They are used around the world to treat hypogonadism and cachexia (Kicman, 2008); however, the misuse of AASs by young people and adults for aesthetic purposes has increased worldwide (Lippi, Franchini, Banfi, 2011), causing many health problems for people of both sexes (Onakomaiya, Henderson, 2016).

Among the AASs used, nandrolone decanoate (ND) stands out as the most commonly used AAS worldwide (Frati et al., 2015). ND is considered an AAS with great

\footnotetext{
*Correspondence: T. U. Andrade. Programa de Pós-graduação em Ciências Farmacêuticas, Universidade Vila Velha/UVV-ES. Rua Comissário José Dantas de Melo, 21, 29102-770 - Boa Vista, Vila Velha, Espírito Santo, Brazil. Tel.: 55-27-3421-2198; Fax: 55-27-3421-2049. Email: tadeu.andrade@uvv.br.

$\S$ In memoriam
}

anabolic capacity and low androgenic effects (Vies, 1985), as implicated by its high affinity for androgenic receptors, and it may even be superior to testosterone itself (Bergink et al., 1985).

Misuse of AASs is characterized by intake of high doses without a medical prescription, which promotes many health complications, especially for the cardiac system (Germanakis et al., 2013; Montisci et al., 2012; Vasilaki et al., 2016). Literature reports have demonstrated the development of cardiac hypertrophy characterized by the addition of sarcomeres, which promotes an increase in the cell volume (Fernandes, Soci, Oliveira, 2011), in addition to arrhythmia and sudden death (Franquni et al., 2013; Riezzo et al., 2014). These negative effects are not limited to the cardiac system, and other negative effects are observed, such as an imbalance of inflammatory cytokines (Franquni et al., 2013; Riezzo et al., 2011), negative effects on the kidney 
(Tsitsimpikou et al., 2016) and development of genetic damage in many tissues (do Carmo et al., 2012).

Additionally, AAS use can promote an imbalance in body physiology, changing key systems for the maintenance of health, such as the renin angiotensin system (RAS) (Andrade et al., 2011; Marques-Neto et al., 2014), an important system that promotes cardiac homeostasis and is involved in pathophysiological conditions (Cowan, Young, 2009). The system is based on enzymes (renin and angiotensin-converting enzyme, ACE) and the synthesis of vasoactive peptides (ANG II, ANG 1.7, ANG 1.9, etc.), which promotes many effects in the body, including increased oxidative stress (Fazeli et al., 2012) via the augmentation of reactive oxidative species (ROS) synthesis by NADPH oxidase. The main route is through AT1 receptor activation by ANG II (Fazeli et al., 2012).

It is well established in the literature that oxidative stress can promote DNA damage (Tonini et al., 2013), and it has also been demonstrated that RAS activation can promote DNA damage (Fazeli et al., 2012; Garrido, Griendling, 2009). Fazeli et al. (2012) showed an increase in DNA damage by AT-1 via NADPH oxidase (isoform Nox 4), thus corroborating the results of Ghorbanihaghjo et al. (2008), who demonstrated that there was a decrease in 8-hydroxy-20-deoxyguanosine (8-OHdG) and DNA damage markers after treatment with losartan or enalapril, which are two RAS blockers.

Oxidative stress is not the only factor that promotes DNA damage; excess DNA replication can also promote it (Kotsantis et al., 2016). It is well known that the effects of ND on the body can be attributed to the modulation of DNA transcription and protein synthesis (Kuhn, 2002). Once in circulation, steroid hormones can cross cell membranes and interact with cytoplasmic receptors. The hormonereceptor complex is then transferred to the nucleus, where it interacts with the nuclear response element and thus promotes gene transcription (Burris et al., 2013).

This process can promote genomic damage, as demonstrated by studies conducted on AAS (do Carmo et al., 2012; Pozzi et al., 2013). do Carmo et al. (2012) observed that ND in high $(5.0 \mathrm{mg} / \mathrm{kg}$ ) or low doses $(1.0 \mathrm{mg} / \mathrm{kg})$ promotes genotoxic effects in different cells of mice, as demonstrated by micronucleus and comet assays. Additionally, Pozzi et al. (2013) observed that ND at doses of 5 and $15 \mathrm{mg} / \mathrm{kg}$ can promote genetic damage in multiple rat organs and that the damage is dose-dependent. The results demonstrated the potential of ND to promote genetic damage in users. However, neither study was conducted to evaluate the genetic or anabolic effects of ND metabolites.
It is well known that testosterone, the male hormone, is biotransformed by two main routes in the body. The first is by the $5 \alpha$-reductase enzyme $(5 \alpha \mathrm{R})$, and the product formed is dihydrotestosterone (DHT), which has higher affinity for androgenic receptors and is therefore considered more potent than testosterone (Tóth and Zakár, 1982). This enzyme is present in tissues that require an androgenic effect, such as the prostate and other sexual tissues (Span et al., 1999).

The same enzymatic pathway is preferred by ND; however, the product of $5 \alpha \mathrm{R}$ action, called dehydronandrolone (DHN), has a lower affinity than does ND for androgenic receptors, resulting in decreased effects of ND (Bergink et al., 1985; Tóth, Zakár, 1982). The main $5 \alpha \mathrm{R}$ inhibitor used in clinical practice is finasteride, which is used for benign prostatic hyperplasia (Goldenberg et al., 2009).

Changes in the biotransformation of ND and testosterone can influence the effects of both hormones; however, no investigation into the effect of ND in combination with $5 \alpha \mathrm{R}$ inhibition on the cardiovascular system or into its mutagenic capacity has been reported. Thus, the aim of the present study was to evaluate the effects of a combination of finasteride, an inhibitor of the $5 \alpha$-reductase enzyme, and ND on the cardiac system and to evaluate the genetic effects of that combination.

\section{MATERIAL AND METHODS}

\section{Experimental animals}

All experiments with animals were performed in agreement with the International Ethical Principles for Animal Use and were approved by the Ethics Committee of Animal Welfare at the University Vila Velha (UVV), Espirito Santo, Brazil (CEUA-UVV; protocol no. 68/2009). Male Wistar rats aged 2-3 months and weighing 200-300 g were housed in individual cages with controlled humidity, temperature and dark-light cycle. The animals were fed a standard chow diet and had access to food and water ad libitum.

The animals were separated into three groups $(n=7$ per group): a) a control group (CONT) that received the vehicles for both drugs (ND and finasteride): peanut oil, intramuscular (i.m.) and saline $0.9 \%$, intraperitoneal (i.p.); b) an ND-treated group (DECA) that received ND (20 $\mathrm{mg} / \mathrm{kg} /$ week, i.m.) (Franquni et al., 2013) and finasteride vehicle (saline $0.9 \%$, i.p.); and c) a combined finasteride and ND group (DECAF) that received both $\mathrm{ND}(20 \mathrm{mg} / \mathrm{kg} / \mathrm{week}, \mathrm{i} . \mathrm{m}$. $)$ and finasteride $(100 \mu \mathrm{g} / \mathrm{kg}$, i.p.; adapted from Rubio-gayosso et al. (2013). 
All treatments were maintained for four weeks; nandrolone decanoate was administered twice a week, and finasteride was administered every $12 \mathrm{~h}$. Nandrolone decanoate (Deca Durabolin ${ }^{\circledR}$ ) was purchased from Organon Inc. (São Paulo, SP, Brazil), and finasteride was purchased from Sigma Chemical Co. (St. Louis, MO, USA).

\section{Determination of cardiac hypertrophy and histological analysis}

At the end of the treatment, the animals were euthanized by decapitation, the blood was collected and centrifuged at $3000 \mathrm{rpm}\left(4^{\circ} \mathrm{C}, 15\right.$ minutes $)$, and the serum was separated and kept at $-80{ }^{\circ} \mathrm{C}$ until use.

The hearts were excised, cleaned and weighed. After the ventricles were fixed in formalin buffer for $24 \mathrm{~h}$ the heart was embedded in paraffin, and a 5 - $\mu$ m-thick slice was stained with hematoxylin/eosin. The slides were evaluated under an optical microscope. For morphometric analyses, ten fields were photographed, and the images were evaluated. The number of myocyte nuclei per highpowered field and the areas and perimeters of the myocyte nuclei were evaluated at $400 \mathrm{X}$ magnification. Image analysis software (Moticam Plus ${ }^{\circledR}$; Motic Inc., Canada) was used, and for each sample, ten high-powered fields were evaluated.

\section{Measurements of the cardiac cytokines and ACE activity}

Part of the ventricles were kept at $-80^{\circ} \mathrm{C}$ to evaluate cytokine (TNF- $\alpha$ and IL-10) levels and angiotensin converting enzyme (ACE) activity. For this, $50 \mathrm{mg}$ of the ventricles were homogenized with phosphate buffer ( $\mathrm{pH}: 8.3$ ), and the protein content was determined by the Bradford method (Bradford, 1976), which was used for cytokine normalization; the result was expressed in picograms per milligram of protein (Meador et al., 2008). All the manufacturer's instructions were followed, and the reading was obtained with an ELISA reader (TP-Reader, Thermoplate).

To analyze ACE activity, a method previously described (Franquni et al., 2013) was followed. Briefly, the ventricle samples were homogenized and incubated with ACE substrate (Hippuryl-Gly-Gly), and the dipeptide formed (Gly-Gly) and was quantified by a reaction with 2,4,6-trinitrobenzenesulfonic acid (TNBS) and read with an ELISA reader (TP-Reader, Thermoplate) at $415 \mathrm{~nm}$. The results are presented as the $\%$ of ACE activity.

\section{Micronucleus assay}

For the micronucleus assay, new experimental groups were formed. The animals were separated into four experimental groups ( $\mathrm{n}=6$ per group): a positive control (PC) group, which received cyclophosphamide $(40 \mathrm{mg} / \mathrm{kg}$, i.p.); a negative control (NC) group, which received the vehicles for ND and finasteride (peanut oil and saline, respectively); a DECA group, which received ND $(20 \mathrm{mg} / \mathrm{kg}$; i.m.) and saline (i.p.); and a DECAF group, which received ND and finasteride (20 mg/kg; i.m., $100 \mu \mathrm{g} / \mathrm{kg})$. All treatments were performed for 3 days. ND was applied $24 \mathrm{~h}$ and $72 \mathrm{~h}$ before the beginning of the protocol, and finasteride was given every 12 hours. This treatment timing has been well established in the literature (Schmid, 1975), and the timing of maturation of bone marrow cells, which was analyzed in the experiment, is well understood.

After the treatments, the animals were euthanized, and their femurs were removed. The assay was performed as previously described (Schmid, 1975). To summarize, a suspension of bone marrow was made using $4 \mathrm{~mL}$ of fetal bovine serum. The supernatant was used to make slides that were fixed with methanol and stained with Leishman stain. For each slide, a total of 1000 cells were counted. For the first 200 cells, both mature/normochromatic erythrocytes (NCEs) and immature/polychromatic erythrocytes (PCEs) were counted. After the first 200 cells, only polychromatic cells were counted. The criteria used to identify the micronuclei were size, shape and color. Overall, 2000 PCEs were counted per animal. The number of micronucleate polychromatic erythrocytes (MNPCE) and the mitotic index (PCE/NCE) were used to verify the cytotoxicity of the compound.

\section{Statistical analysis}

The results are expressed as the mean \pm standard error of the mean (S.E.M.). The data were analyzed using a one-way ANOVA with a post hoc Tukey test. For the micronucleus assay, the results are expressed as the mean \pm standard deviation (S.D.). Statistical significance was defined as $p<0.05$. The software GB-Stat ${ }^{\circledR}$ was used for statistical analysis, and Slide Write was used for the graphical representations.

\section{RESULTS}

\section{Histological and morphometric analyses}

The combination of DECA with finasteride treatment increased cardiac hypertrophy in the DECAF 
group compared with the CONT and DECA groups. Figure 1 shows the cardiac morphometry results for the experimental groups, which revealed a reduction in the number of nuclei per high-powered field in animals that received ND that was approximately $37.29 \%$ lower than CONT group and $47.19 \%$ lower than the reduction after treatment with the combination of ND and finasteride (DECAF; Figure 1D). This reduction was followed by an increase in the myocyte nucleus area (DECA $12.8 \%$; DECAF 22.67\%; Figure 1E) and the perimeter (DECA 9.1\%; DECAF 15.03\%; Figure 1F) compared with those in the CONT animals.

\section{Cardiac cytokine analysis (TNF- $\alpha$ and IL-10) and ACE activity}

Inhibition of the $5 \alpha$-reductase $(5 \alpha \mathrm{R})$ pathway by finasteride promoted an increase in inflammatory imbalance in the DECAF group compared to that in the CONT group (Figure 2, panels A-C). The treatment with ND caused an increase in the TNF- $\alpha$ level (DECA: $24.8 \%$; DECAF: $40.7 \%$ compared to CONT) and promoted a decrease in the IL-10 content (DECA: 14.4\%; DECAF: $26.9 \%$ compared to CONT), thus increasing the proinflammatory/anti-inflammatory cytokine ratio, which
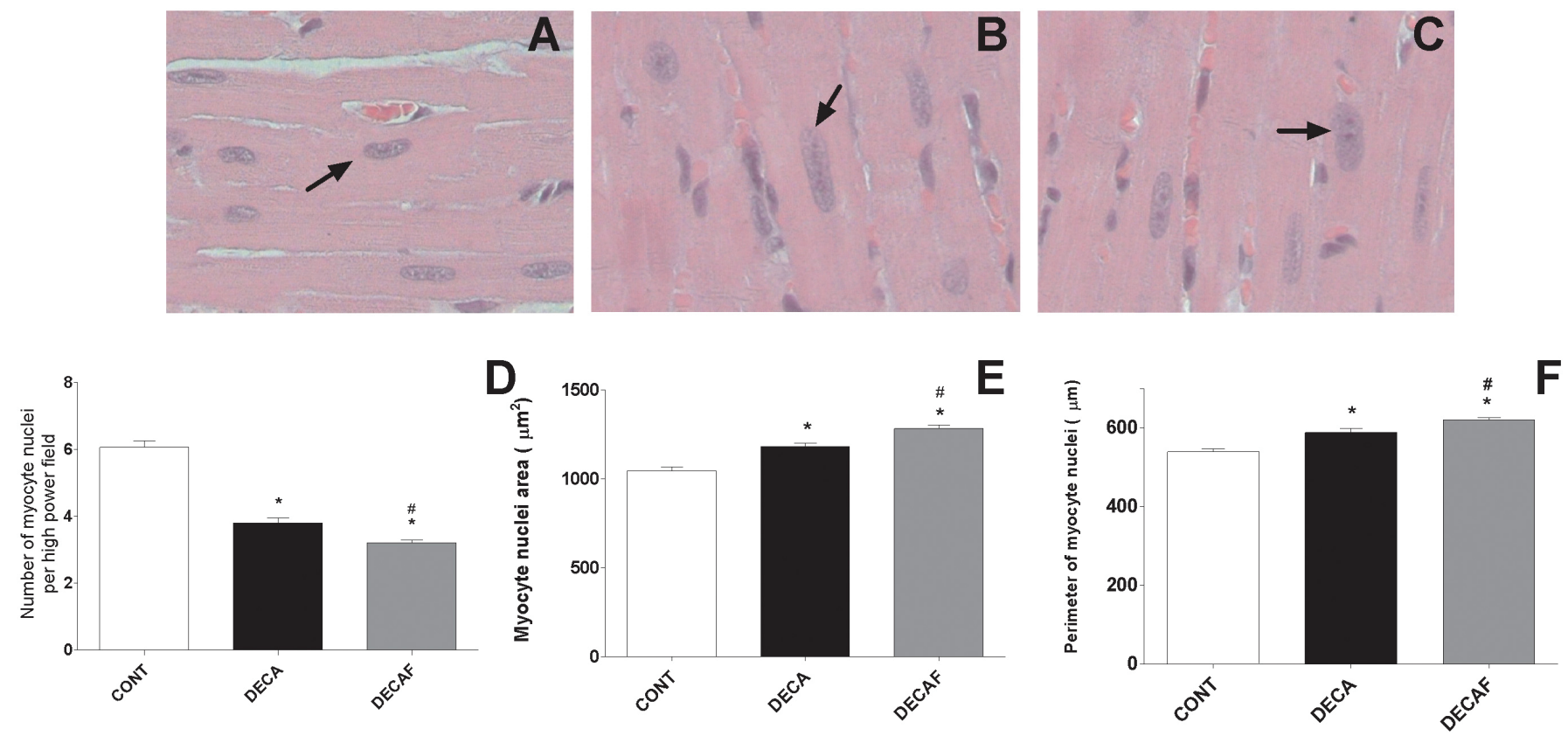

FIGURE 1 - Results of the morphometric analysis of the left ventricle of animals treated with ND and finasteride. Representative samples of the histologic analysis (Panels A-C); the arrows indicate the representative nucleus in the histologic samples. Panel D: Analysis of the number of cardiac myocyte nuclei after treatment with the combination of ND and finasteride compared to that of the control group. Panel E: Area of myocyte nuclei after treatment compared to that of the control group. Panel F: Perimeter analysis of the myocyte nuclei after treatment. ${ }^{*} \mathrm{p}<0.05$ compared to the control group. \# $\mathrm{p}<0.05$ compared to the DECA group.
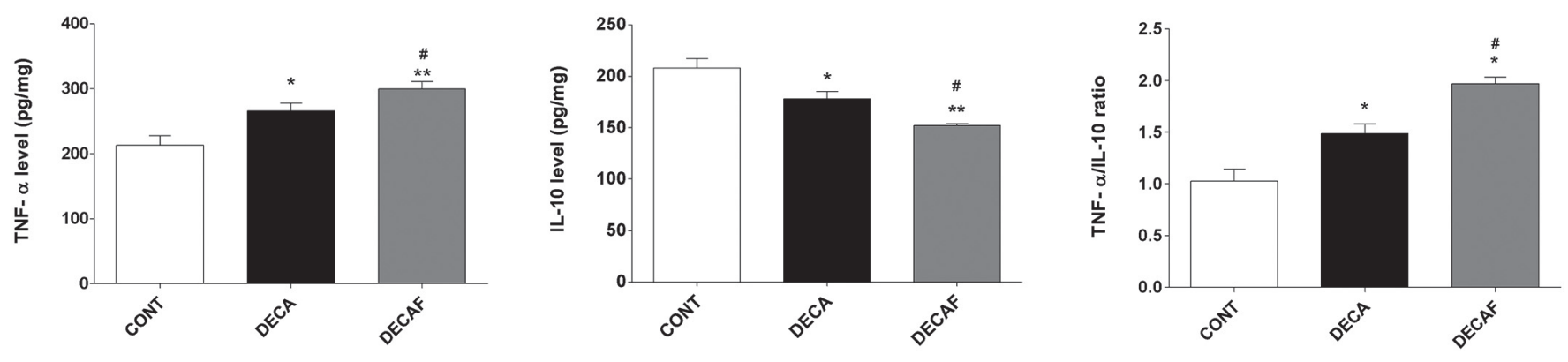

FIGURE 2 - Effects of treatment with ND in combination with finasteride on serum cytokines. Panel A: TNF- $\alpha$ levels were increased after cotreatment with finasteride and ND. Panel B: IL-10 levels were decreased after treatment. Panel C: Imbalance of the TNF- $\alpha /$ IL-10 ratio after treatment. ${ }^{*} \mathrm{p}<0.05$ and $* * \mathrm{p}<0.01$ compared to the CONT group. $\# \mathrm{p}<0.05$ compared to the DECA group. 


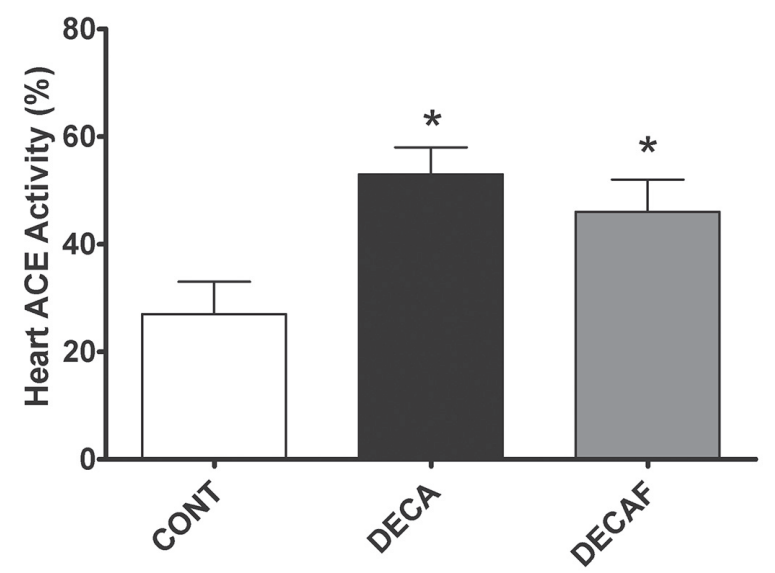

FIGURE 3 - ACE activity (\%) after treatment with ND with or without finasteride. CONT - animals received vehicles (peanut oil and saline). DECA - animals received ND (20 mg/kg/week); DECAF - animals received ND in combination with finasteride $(100 \mu \mathrm{g} / \mathrm{kg}) .{ }^{*} \mathrm{p}<0.05$ compared to the CONT group.

confirmed the imbalance of these cytokines in the treated animals. The addition of finasteride promoted a greater inflammatory response than that in the DECA group.

ACE activity was also measured in the left ventricle samples. ND treatment promoted an increase in ACE activity compared with that of the CONT group (CONT: $27.0 \pm 6 \%$; DECA: $53 \pm 5 \%$; DEAF: $46 \pm 6 \%$ ); however, the addition of finasteride did not increase the activity compared to that in the DECA group $\left({ }^{*} p<0.05\right.$ compared to CONT; Figure 3).

\section{Micronucleus assay analysis}

Table I shows the results of the evaluation of the cytotoxic and genotoxic effects in the DECA group with finasteride treatment. There was an increase in the number of MNPCE $(p<0.01$ compared to the NC group) and a reduction in the mitotic index $(\mathrm{p}<0.01$ compared to the $\mathrm{NC}$ group) in the group treated with ND alone, which was consistent with the change promoted by cyclophosphamide. Additionally, when ND was combined with finasteride, a decrease in MNPCE and a reestablishment of the mitotic index were observed ( $p<0.01$ compared to the $\mathrm{NC}$ group).

\section{DISCUSSION}

The main finding of the present study was the worsening of cardiac effects after application of a combination of ND and finasteride, an inhibitor of $5 \alpha \mathrm{R}$. In the DECAF group, cardiac hypertrophy and the imbalance between pro- and anti-inflammatory cytokines were intensified. Additionally, ACE activity was increased. Interestingly, the genotoxic effects promoted by nandrolone decanoate were attenuated when it was combined with finasteride.

It is well known that ND can promote concentric cardiac hypertrophy associated with cardiac remodeling (Andrade et al., 2011; Brasil et al., 2015; Franquni et al., 2013) and that cardiovascular effects are combined with an imbalance among pro- and anti-inflammatory cytokine concentrations (Franquni et al., 2013). However, this is the first time that the worsening of these parameters has been demonstrated after enzymatic inhibition, suggesting that ND, not its metabolite DHN, is the most important molecule involved in these results.

Under physiological conditions, $5 \alpha \mathrm{R}$ promotes amplifies testosterone signaling as a result of increases in androgen receptor affinity (Bergink et al., 1985). Rubiogayosso et al. (2013) demonstrated that inhibition of $5 \alpha \mathrm{R}$ enzymes by finasteride promotes a decrease in infarcted areas, resulting in cardiac protection after ischemia and reperfusion. These results demonstrate the deleterious effects of DHT on cardiac tissue.

Additionally, previous reports have demonstrated that androgens present different affinities for androgenic receptors (Kumar et al., 1999; Tóth, Zakár, 1982). In comparison, nandrolone has greater affinity for androgenic receptors than do testosterone and DHN; however, DHT present the greatest receptor affinity among all these

TABLE I - Number of normochromatic erythrocytes (NCE), micronucleated polychromatic erythrocytes (MNPCE) or not (PCE), and the mitotic index each group (relation PCE/NCE) in bone marrow of Wistar rats treated with DN. Result of the analysis of two thousand cells

\begin{tabular}{lcccc}
\hline Group & NCE & PCE & MNPCE & Mitotic Index \\
\hline NC & $90.4 \pm 11.26$ & $111.6 \pm 13.52$ & $2.4 \pm 1.14$ & $1.26 \pm 0.30$ \\
PC & $146.6 \pm 4.39^{*}$ & $55.4 \pm 5.22^{*}$ & $54.6 \pm 4.77^{*}$ & $0.38 \pm 0.04^{*}$ \\
DECA & $160.67 \pm 4.16^{*}$ & $46.33 \pm 9.71^{*}$ & $22.0 \pm 7.55^{*}$ & $0.29 \pm 0.06^{*}$ \\
DECAF & $88.2 \pm 10.80$ & $111.6 \pm 10.64$ & $3.9 \pm 1.14$ & $1.29 \pm 0.28$ \\
\hline
\end{tabular}

Data are presented as mean \pm Standard deviation; * Significantly different from negative control $(p<0.01)$. 
molecules (Kumar et al., 1999; Tóth, Zakár, 1982). Based on these results, we can infer that, in cardiac tissue, inhibition of $5 \alpha \mathrm{R}$ promotes an increase in ND bioavailability and a decrease in DHT, which can explain the finding that the greatest hypertrophy occurred in the DECAF group. The hypertrophy observed in the heart is not limited to that tissue (Brasil et al., 2015).

The capability of AASs to promote muscle growth and improve athletic performance is the main reason for their misuse worldwide, which occurs for aesthetic purposes only without any medical assistance (Abrahin, de Sousa, Santos, 2014). As demonstrated previously, the deleterious cardiac effects are not limited to hypertrophy, which can be defined as an increase in cardiomyocyte volume upon the addition of sarcomeres (Fernandes, Soci, Oliveira, 2011), but also include promotion of the development of hypertension, arrhythmias, cardiac fibrosis and sudden death, as demonstrated in clinical and experimental approaches (Darke, Torok, Duflou, 2014; Franquni et al., 2013; Montisci et al., 2012; Paolo et al., 2007).

Studies have demonstrated that the deleterious effects promoted by ND can be attributed, at least in part, to RAS activation (Marques-neto et al., 2014). Marquesneto et al., 2014 showed that treatment with ND can reduce exercise-mediated cardioprotection against ischemiareperfusion; however, when AT1 receptors are blocked, this effect is prevented.

Additionally, Andrade et al. (2011) demonstrated that inhibition of ACE by enalapril reversed the cardiac effects promoted by ND, indicating that the enzyme plays a key role in the effects of AAS. Our results demonstrated an increase in ACE activity in the DECA and DECAF groups, indicating that activation of that enzyme occurs even when metabolism is induced by $5 \alpha \mathrm{R}$ enzymes. Therefore, we can infer that ACE activity is involved in cardiac hypertrophy, as previously demonstrated (Dalpiaz et al., 2015), and that AAS metabolism has no effect on ACE activation. On the other hand, the combined treatment of ND and finasteride worsened the imbalance of cytokines, increasing inflammation. Other previous studies have demonstrated the negative effects of AASs on inflammatory cytokines (Franquni et al., 2013; Lima et al., 2015) and have revealed that the relationship can be related to the activation of androgenic receptors (ARs). For example, Huang et al. (2014) demonstrated that when the AR gene is silenced in monocytes/macrophages and other cells, there is a reduction in TNF- $\alpha$ gene expression. Additionally, they concluded that AR exerts a positive effect on TNF- $\alpha$ release. Thus, we can infer that inhibiting the conversion of ND to DHN with finasteride promotes the greatest activation of ARs. The fact that ND has a greater AR affinity than testosterone can explain the increase in TNF- $\alpha$ observed after finasteride treatment.

Finally, treatment with finasteride promoted a decrease in the micronuclei and cytotoxicity promoted by ND. Some authors have demonstrated that RAS is involved in DNA damage (Fazeli et al., 2012; Ghorbanihaghjo et al., 2008; Ozcagli et al., 2018). We can infer that this is the possible mechanism involved in NDinduced DNA damage, as ACE activity was increased in the DECA group. However, no difference in ACE activity was observed in the DECAF group that also received finasteride, demonstrating that finasteride may confer some protective effect in bone marrow.

Some authors have demonstrated antioxidant effects promoted by finasteride (Kolasa-Wołosiuk et al., 2017; Mladenović et al., 2015; Nambiar, Singh, 2013; Yun, Lee, Keum, 2013). Mladenović et al. (2015) demonstrated that pretreatment with finasteride prevents the negative effects of thioacetamide by increasing SOD1 and catalase activity. Yun, Lee and Keum (2013) showed that treatment of prostatic cancer cells with finasteride promoted increased NF-E2-related factor-2 (Nrf2) protein expression. This factor is associated with increases in the synthesis of antioxidant enzymes such as SOD, catalase and glutathione peroxidase (Kansanen et al., 2013). Together, these results demonstrate that finasteride promotes antioxidant responses, which can explain our results in bone marrow cells.

In conclusion, we demonstrated that ND metabolism promoted different results in cardiac and bone marrow tissues. An increase in deleterious effects was observed in cardiac tissues, while a protective effect was found in bone marrow tissues. The discrepant results can be linked to the different mechanisms involved in each type of tissue.

\section{ACKNOWLEDGEMENTS}

We thank FAPES for financial support (TO: 0279/2016).

\section{REFERENCES}

Abrahin OSC, de Sousa EC, Santos AM. Prevalence of the use of anabolic-androgenic steroids in Brazil: a systematic review. Subst Use Misuse. 2014;49(9):1156-62.

Andrade TU De, Loiola LZ, Merces S, Alcure N, Raquel A, Medeiros S, et al. Role of the renin - angiotensin system in the nandrolone-decanoate-induced attenuation of the Bezold - Jarisch reflex. Can J Physiol Pharmacol. 2011;89(12):891-7. 
Bergink EW, Janssen PSL, Turpijn EW, Vies J Van der. Comparison of the receptor binding properties of nandrolone and testosterone under in vitro and in vivo conditions. J Steroid Biochem. 1985;22(6):831-6.

Bradford MM. A rapid and sensitive method for the quantitation of microgram quantities of protein utilizing the principle of protein-dye binding. Anal Biochem. 1976;72:248-54.

Brasil GA, Lima EM de, Nascimento AM do, Caliman IF, Medeiros ARS de, Silva MSB, et al. Nandrolone decanoate induces cardiac and renal remodeling in female rats, without modi fi cation in physiological parameters : The role of ANP system. Life Sci. 2015;137:65-73.

Burris TP, Solt LA, Wang Y, Crumbley C, Banerjee S, Griffett $\mathrm{K}$, et al. Nuclear receptors and their selective pharmacologic modulators. Pharmacol Rev. 2013;65(2):710-78.

do Carmo CA, Gonçalves ÁLM, Salvadori DMF, Maistro EL. Nandrolone androgenic hormone presents genotoxic effects in different cells of mice. J Appl Toxicol. 2012;32(10):810-4.

Cowan BR, Young AA. Left ventricular hypertrophy and renin-angiotensin system blockade. Curr Hypertens Rep. 2009;11(3):167-72.

Dalpiaz PLM, Lamas AZ, Caliman IF, Ribeiro RF, Abreu GR, Moyses MR, et al. Sex hormones promote opposite effects on ACE and ACE2 activity, hypertrophy and cardiac contractility in spontaneously hypertensive rats. PLoS One. 2015;10(5):1-15.

Darke S, Torok M, Duflou J. Sudden or unnatural deaths involving anabolic-androgenic steroids. J Forensic Sci. 2014;59(4):1025-8.

Fazeli G, Stopper H, Schinzel R, Ni CW, Jo H, Schupp N. Angiotensin II induces DNA damage via AT1 receptor and NADPH oxidase isoform Nox4. Mutagenesis. 2012;27(6):673-81.

Fernandes T, Soci UPR, Oliveira EM. Eccentric and concentric cardiac hypertrophy induced by exercise training: microRNAs and molecular determinants. Braz J Med Biol Res. 2011;44(9):836-47.

Franquni JVM, Nascimento AM do, Lima EM de, Brasil GA, Heringer OA, Cassaro KO dos S, et al. Nandrolone decanoate determines cardiac remodelling and injury by an imbalance in cardiac inflammatory cytokines and ACE activity, blunting of the Bezold - Jarisch reflex, resulting in the development of hypertension. Steroids. 2013;78(3):379-85.
Frati P, Busardò FP, Cipolloni L, Dominicis E De, Fineschi V. Anabolic Androgenic Steroid (AAS) related histopathological and toxicological findings deaths: autoptic, histopathological and toxicological findings. Curr Neuropharmacol. 2015;336(1):14659.

Garrido AM, Griendling KK. NADPH Oxidases and angiotensin II receptor signaling. Mol Cell Endocrinol. 2009;302(2):148-58.

Germanakis I, Tsarouhas K, Fragkiadaki P, Tsitsimpikou C, Goutzourelas N, Champsas MC, et al. Oxidative stress and myocardial dysfunction in young rabbits after short term anabolic steroids administration. Food Chem Toxicol. 2013;61:101-5.

Ghorbanihaghjo A, Veisi P, Argani H, Aghaeishahsavari M, Noroozianavval M, Rashtchizadeh N, et al. Prevention of DNA damage in renal transplantation by losartan and enalapril: The role of renin-angiotensin system polymorphisms. Clin Exp Nephrol. 2008;12(1):65-73.

Goldenberg L, So A, Fleshner N, Rendon R, Drachenberg D, Elhilali $\mathrm{M}$. The role of 5-alpha reductase inhibitors in prostate pathophysiology: Is there an additional advantage to inhibition of type 1 isoenzyme? J Can Urol Assoc. 2009;3(3Suppl 2):10914.

Huang CK, Pang H, Wang L, Niu Y, Luo J, Chang E, et al. New therapy via targeting androgen receptor in monocytes/ macrophages to battle atherosclerosis. Hypertension. 2014;63(6):1345-53.

Kansanen E, Kuosmanen SM, Leinonen H, Levonenn AL. The Keap1-Nrf2 pathway: Mechanisms of activation and dysregulation in cancer. Redox Biol. 2013;1:45-9.

Kicman AT. Pharmacology of anabolic steroids. Br J Pharmacol. 2008;154(3):502-21.

Kolasa-Wołosiuk A, Tarnowski M, Baranowska-bosiacka I, Chlubek D, Wiszniewska B. Antioxidant enzyme expression of mRNA and protein in the epididymis of finasteride-treated male rat offspring during postnatal development. Arch Med Sci. 2017:1-14.

Kotsantis P, Silva LM, Irmscher S, Jones RM, Folkes L, Gromak $\mathrm{N}$, et al. Increased global transcription activity as a mechanism of replication stress in cancer. Nat Commun. 2016;7:1-13.

Kuhn CM. Anabolic steroids. Recent Prog Horm Res. 2002;57:411-34. 
Kumar N, Crozat A, Li F, Catterall JF, Bardin CW, Sundaram K. 7 alpha-methyl-19-nortestosterone, a synthetic androgen with high potency: structure-activity comparisons with other androgens. J Steroid Biochem Mol Biol. 1999;71(5-6):213-22.

Lima EM, Nascimento AM, Brasil GA, Kalil IC, Lenz D, Endringer DC, et al. Cardiopulmonary reflex, cardiac cytokines, and nandrolone decanoate: response to resistance training in rats. Can J Physiol Pharmacol. 2015;93(11):985-91.

Lippi G, Franchini M, Banfi G. Biochemistry and physiology of anabolic androgenic steroids doping. Mini Rev Med Chem. 2011;11(5):362-73.

Marques-neto SR, Ferraz EB, Rodrigues DC, Njaine B, Rondinelli E, Carvalho ACC de, et al. AT1 and aldosterone receptors blockade prevents the chronic effect of nandrolone on the exercise-induced cardioprotection in perfused rat heart subjected to ischemia and reperfusion. Cardiovasc Drugs Ther. 2014;28(2):125-35.

Meador BM, Krzyszton CP, Johnson RW, Huey KA, Peake J, Gatta P Della, et al. Effects of IL-10 and age on IL-6, IL-1 $\beta$, and TNF- $\alpha$ responses in mouse skeletal and cardiac muscle to an acute inflammatory insult. J Appl Physiol. 2008;104(4):991-7.

Mladenović D, Petronijević N, Stojković T, Velimirović M, Jevtić G, Hrnčić D, et al. Finasteride has regionally different effects on brain oxidative stress and acetylcholinesterase activity in acute thioacetamide-induced hepatic encephalopathy in rats. PLoS One. 2015;10(8):e0134434.

Montisci M, Mazloum R El, Cecchetto G, Terranova C, Ferrara SD, Thiene G, et al. Anabolic androgenic steroids abuse and cardiac death in athletes : Morphological and toxicological findings in four fatal cases. Forensic Sci Int. 2012;217(1-3):e127.

Nambiar D, Singh RP. Advances in prostate cancer chemoprevention: A translational perspective. Nutr Cancer. 2013;65(Suppl 1):12-25.

Onakomaiya MM, Henderson LP. Mad men, women and steroid cocktails : a review of the impact of sex and other factors on anabolic androgenic steroids effects on affective behaviors. Psychopharmacology (Berl). 2016;233(4):549-69.

Ozcagli E, Kara MP, Kotil T, Fragkiadaki P, Tzatzarakis MN, Tsitsimpikou C, et al. Stanozolol administration combined with exercise leads to decreased telomerase activity possibly associated with liver aging. Int J Mol Med. 2018;42(1):405-13.
Paolo M Di, Agozzino M, Toni C, Luciani AB, Molendini L, Scaglione M, et al. Sudden anabolic steroid abuse-related death in athletes. Int J Cardiol. 2007;114(1):114-7.

Pozzi R, Fernandes KR, Moura CFG de, Ferrari RAM, Fernandes KPS, Renno ACM, et al. Nandrolone decanoate induces genetic damage in multiple organs of rats. Arch Environ Contam Toxicol. 2013;64(3):514-8.

Riezzo I, Paolo M Di, Neri M, Bello S, Cantatore S, Errico $\mathrm{SD}$, et al. Anabolic steroid - and exercise - induced cardiodepressant cytokines and myocardial 1 receptor expression in CD1 mice. Curr Pharm Biotechnol. 2011;12(2):275-84.

Riezzo I, Turillazzi E, Bello S, Cantatore S, Cerretani D, Paolo $\mathrm{M}$ Di, et al. Chronic nandrolone administration promotes oxidative stress, induction of pro-in fl ammatory cytokine and TNF- $\alpha$ mediated apoptosis in the kidneys of CD1 treated mice. Toxicol Appl Pharmacol. 2014;280(1):97-106.

Rubio-gayosso I, Ramirez-sanchez I, Ita-islas I, Ortiz-vilchis P, Gutierrez-salmean G, Meaney A, et al. Testosterone metabolites mediate its effects on myocardial damage induced by ischemia/ reperfusion in male Wistar rats. Steroids. 2013;78(3):362-9.

Schmid W. The micronucleous test. Mutat Res. 1975;31(1):9-15.

Span PN, Völler MCW, Smals AGH, Sweep FGJ, Schalken JA, Feneley MR, et al. Selectivity of Finasteride as an in vivo inhibitor of 5-alpha reductase isozyme enzymatic activity in the human prostate. J Urol. 1999;161(1):332-7.

Tonini CL, Campagnaro BP, Louro LPS, Pereira TMC, Vasquez EC, Meyrelles SS. Effects of aging and hypercholesterolemia on oxidative stress and DNA damage in bone marrow mononuclear cells in apolipoprotein E-deficient mice. Int J Mol Sci. 2013;14(2):3325-42.

Tóth M, Zakár T. Relative binding affinities of testosterone, 19-nortestosterone and thei 5-alpha-reduced derivatives to the androgen receptor and to other andogen-binding proteins: A suggested role of 5-alpha-reductive steroid metabolism in the dissociation of "myotropic. J Steroid Biochem. 1982;17(6):65360 .

Tsitsimpikou C, Vasilaki F, Tsarouhas K, Fragkiadaki P, Tzardi M, Goutzourelas N, et al. Nephrotoxicity in rabbits after long-term nandrolone decanoate administration. Toxicol Lett. 2016;259:21-7. 
Vasilaki F, Tsitsimpikou C, Tsarouhas K, Germanakis I, Tzardi $\mathrm{M}$, Kavvalakis M, et al. Cardiotoxicity in rabbits after long-term nandrolone decanoae administration. Toxicol Lett. 2016;259:217.

Vies J van der. Implications of basic pharmacology in the therapy with esters of nandrolone. Acta Endocrinol (Copenh). 1985;Suppl:38-44.
Yun DK, Lee J, Keum YS. Finasteride increases the expression of hemoxygenase-1 (HO-1) and NF-E2-related factor-2 (Nrf2) proteins in PC-3 cells: Implication of finasteride-mediated highgrade prostate tumor occurrence. Biomol Ther. 2013;21(1):4953.

Received for publication on $20^{\text {th }}$ April 2018 Accepted for publication on $23^{\text {rd }}$ September 2018 